
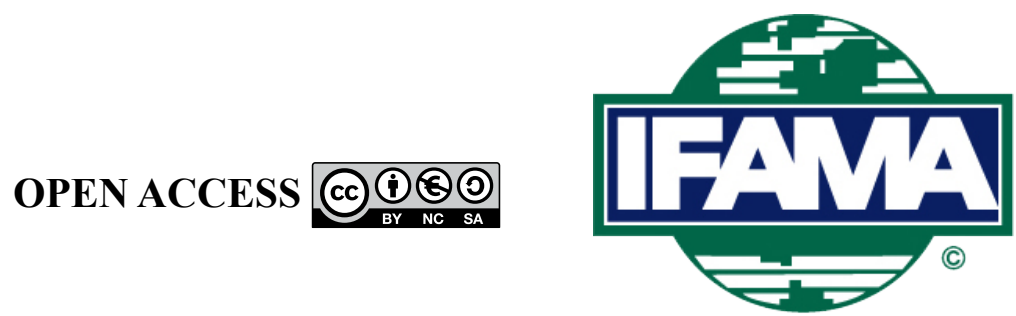

International Food and Agribusiness Management Review

Volume 25, Issue 2, 2022; DOI: 10.22434/IFAMR2021.0056

Received: 10 May 2021 / Accepted: 7 July 2021

\title{
It takes two to tango: combining asset specificity and uncertainty to explain the diversity of plural forms
}

\section{RESEARCH ARTICLE}

\author{
Paula Sarita Bigio Schnaider ${ }^{\circledR a}$, Maria Sylvia Macchione Saes ${ }^{\mathrm{a}}$ and Emmanuel Raynaud ${ }^{\mathrm{b}}$ \\ ${ }^{a}$ Professor, University of Sao Paulo, School of Economics, Business and Accounting, Center for \\ Organization Studies - CORS, Av Professor Luciano Gualberto, 908, Sao Paulo - SP, 05510 - 08, Brazil \\ ${ }^{b}$ Professor, UMR SADAPT, AgroParisTech, INRAE, Université Paris- \\ Saclay, 16 rue Claude Bernard, 75231, Paris cedex 05, France
}

\begin{abstract}
In this paper, we rely on an extended version of the traditional transaction cost economics (TCE) framework to explain the variety of plural forms in the governance of food supply chains. Relying on the interplay of two transactional attributes - asset specificity and uncertainty - we explore not only the existence of plural forms, but their empirical diversity. This aspect has been largely under-explored and very little has been done empirically so far in this respect, despite its empirical significance. From an organizational point of view, this diversity requires an explanation as they carry different governance properties. We propose that while both are important drivers for the prevalence of plural forms, each of them plays a different role in their composition. Whereas uncertainty determines the type of plural form, asset specificity determines the level of coordination within the plural form and sheds light in the relative weights of each organizational arrangement composing it. An embedded case study of the Korin firm in Brazil, a leading firm in the organic food market, illustrates.
\end{abstract}

Keywords: asset specificity, uncertainty, food supply chains, governance, plural forms, transaction costs JEL code: D23, D21, Q10, L66

\footnotetext{
${ }^{\circledR}$ Corresponding author: paula.schnaider@usp.br
} 


\section{Introduction}

Food supply chains, have for long been fertile ground to confront transaction cost economics (TCE) determinants of organizational choices (Férnandez-Barcala et al., 2017; Ghozzi et al., 2016; Macher and Richman, 2008; Masten, 2000; Ruben et al., 2007; Vinholis et al., 2014; Zylbersztajn, 1996). Sourcing (distribution) transactions within agri-food supply chains are organized in very diverse ways. Some firms obtain (distribute) their inputs (products) in a totally integrated way, while others rely on outsourced suppliers (retailers). More recently, however, scholars have started to acknowledge a variety of organizational arrangements that go beyond the 'make or buy' decision (Baker et al., 2008; Williamson, 1985): 'hybrid organizations' (Ménard, 2018). Hybrids represent a type of governance structure in which parties go beyond market price to organize their transactions without relying on vertical integration. Long-term contracts, equity joint-ventures, strategic alliances are leading examples. ${ }^{1}$

In addition, many firms in various industrial sectors are simultaneously recurring to alternative organizational arrangements to procure inputs bearing roughly the same level of transactional attributes, the so-called plural forms. ${ }^{2}$ The canonical example is franchising in which most franchised chains rely on both franchised and company-owned units in local markets with similar characteristics (Bradach, 1998; Bradach and Eccles, 1989; Lafontaine, 1992). Upstream, Carrer et al. (2014) demonstrate that beef processing companies simultaneously obtain beef by formally or informally contracting with cattle and on the spot market and through vertical integration. Similar results have been found in the sugarcane sector in Brazil (Feltre and Paulillo, 2015) and in 24 agribusiness firms, in various sectors, in the same country (Ménard et al., 2014).

While a lot has been discussed on the different modalities to organize outsourcing, namely the different types of hybrid organizations, the diversity of modalities composing the so-called plural forms has remained under-explored despite its empirical significance. From an organizational point of view, this diversity requires an explanation as they carry different governance properties.

This paper follows the scarce number of contributions (Dutta et al., 1995; Ghozzi et al., 2018; Krzeminska, 2009; Ménard, 2013; Parmigiani, 2007; Schnaider et al., 2018) extending the classical TCE model to explain the existence and prevalence of plural forms in many industrial settings. Most of these previous contributions rely on the interplay between two of TCE's transactional attributes: asset specificity and uncertainty. ${ }^{3}$ They do not however, investigate the variety of plural forms, namely the diversity in the combination of alternative governance structures (Schnaider et al., 2018, is an exception). These combinations, the essence of plural forms, go beyond the reliance on both market and vertical integration which has been the main focus of most of the previous literature. Firms can combine hybrids with vertical integration (like in franchising), markets and hybrids and so on. In addition, different firms can rely on the same type of plural forms (say formal and relational contracts) with different weights attached to each of these individual governance forms. To illustrate this diversity, Ménard et al. (2014) found that a chocolate producer relies on both relational and formal contracts to procure cocoa on a 45-55 ratio, while a roasted \& ground coffee firm relies on the same arrangements to procure Robusta coffee on a 80-20 ratio. Firms can even use more than two different governance structures to manage a transaction. How can TCE determinants explain or even predict these differences?

This paper goes in this direction. We intend to explore how the combination of asset specificity and uncertainty drive the variety of plural forms. We also intend to explore their respective roles in the composition of the plural form and hence, develop some empirical propositions predicting the type of plural form that would be chosen given the set of drivers. It does so by relying on a case study in the Brazilian agrifood sector. We perform an embedded clinical case study (Baker and Gil, 2013; Yin, 2011) at the Korin firm in Brazil. Despite the shortcomings of case studies (Baker and Gil, 2013), we rely on this empirical approach because

\footnotetext{
${ }^{1}$ For a discussion about hybrid arrangements and their variety in agrifood supply chains, see Grandori (2015) and Ménard (2018).

${ }^{2}$ For a comprehensive survey on this aspect, see Raynaud et al. (2019).

${ }^{3}$ Ménard (2013) is an exception as he explained plural forms by introducing additional transactional characteristics.
} 
of the lack of previous studies on the diversity of plural forms that goes beyond 'make and buy' and because this research aims for theoretical developments (Siggelkow, 2007). ${ }^{4}$ In addition, relying on a single case while looking at the governance of several transactions within the case is an interesting method because all these different transactions occur within the same firm and the same country, allowing us to keep constant institutional and firm specific variables, such as size, culture, strategic orientation and the like. Consequently, we can better focus solely on our variables of interest (Yin, 2011). Our case-based empirical analysis should be seen as an illustration of the empirical diversity that we intend to describe and explain (Baker and Gil, 2013; Eisenhardt, 1989; Yin, 2011). The Korin company (described in more details later on) produces and sells a wide variety of organic food, such as poultry, eggs and vegetables - each of which subject to distinct levels of asset specificity and uncertainty - and relies on different types of arrangements to organize its procurement.

The paper is structured as follows. First, some theoretical propositions are derived from the two important transaction cost determinants often associated to the use of plural forms: asset specificity and uncertainty (Ménard, 2013; Schnaider et al., 2018). Next, we develop some propositions to account for the diversity of plural form manifestations. Finally, we confront our propositions with empirical data in an agribusiness setting. Conclusions follow.

\section{Theoretical framework}

\subsection{Transaction cost economics determinants}

The predictive power of TCE to explain organizational choices heavily relies on the idea that, under competitive pressure, firms will try to efficiently align their governance decisions to the hazards they face in the management of a given transaction (Fernández-Olmos et al., 2009; Williamson, 1985, 1991, 2008; Woldie and Nuppenau, 2011) in order to economise on transaction costs. In the empirical literature on organizational decisions, the most studied explanatory factor has been the level of specific investments (David and Han, 2004; Masten, 2000). Nonetheless, recent contributions have recognized that the quest for efficiency in TCE goes way beyond this 'asset specificity story' in the sense that the efficient choice results from the interplay of asset specificity and other transactional attributes such as uncertainty (Krzeminska, 2009; Parmigiani, 2007; Raynaud et al., 2019; Schnaider et al., 2018; Williamson, 1991). They have, therefore, sought to extend the basic model to encompass plural forms, relying on this idea. While they recognize that 'standard' hybrids might deteriorate under high uncertainty (Williamson, 1991), the authors provide alternative solutions that might outperform spot markets and hierarchies in this case. The basic idea is that there are cheaper ways of establishing safeguards and encouraging adaptations to deal with high levels of uncertainty, when asset specificity is of an intermediate level, than pure markets or hierarchies. In fact, Bradach and Eccles (1989) were one of the first to demonstrate the advantages of using plural forms. Later, the empirical results in Parmigiani (2007) and Menard et al. (2014) provide exploratory evidence in favor of the use of plural forms to deal with asset specificity and significant uncertainty. This is why Krzeminska (2009), Schnaider et al. (2018) and Ghozzi et al. (2018) propose that:

Proposition 1: Intermediate levels of asset specificity, together with significant levels of uncertainty, motivate the choice for plural forms.

This is summarized in Figure 1, where the horizontal axis represents the level of contractual hazards related to asset specificity while the vertical axis is the level of uncertainty. When the level of uncertainty is relatively low (below U1), the standard asset specificity story holds. However, as the level of uncertainty grows, the interplay of these two variables becomes increasingly central to efficiently organizing transactions (Williamson, 1991). Nonetheless, because of the bilateral dependency related to non-redeployability of specific investments,

\footnotetext{
${ }^{4}$ Our clinical case studies hold similarities with grounded theory (Eisenhardt, 1989; Glaser and Strauss, 1967; Strauss, 1987), as they both intend to provide new theoretical developments and are based on empirical observation.
} 
asset specificity is still a key variable, and hence, even when uncertainty is high, markets and hierarchies are still best when asset specificity is very low or very high. However, under high levels of uncertainty (above U1) and intermediate asset specificity, arranging and rearranging coordinated responses becomes non-trivial and therefore, plural forms might develop in the central grey zone in Figure 1 (P1).

\subsection{Heterogeneity of plural forms}

The mere recognition that TCE might play an important role in the plural form debate is already an important step toward an integrated theory of this phenomenon. An additional step is recognizing that plural forms are not a uniform category of arrangements, but rather a general designation for several different types of combinations, presenting very different characteristics. For instance, Figure 1 is silent about the bilateral governance structures that are combined in the plural form area.

A first attempt to categorize this diversity is presented in Schnaider et al. (2018), who define three generic types of plural forms, grouping together different manifestations with similar characteristics. First, the 'between type', designates firms that combine, in different ways, two of the three main families of bilateral governance structures (i.e. sport market + hierarchy; or spot market + hybrids; or hierarchy + hybrids, etc). The well-known 'make-and-buy', prevalent in franchising (Lafontaine and Shaw, 2005), is a typical example of the 'between' type of plural forms. The second group constitutes the 'within type', designating the use of different types of typical hybrid arrangements to organize similar transactions (i.e. relational contracts + long-term contracts; allices + short-term contracts, etc). The organization of some automotive firms in Japan illustrates this type of plural forms (Dyer, 1996). Finally, the 'combo type', contemplates the case where firms combine the two previous types of plural forms, sometimes with different weights (for instance spot market + relational contracts + long-term formal contracts, etc).

As such diversity becomes recognized, a key issue becomes to explain its determinants. One way of doing so is to seek explanations for the choice of each of the categories specified above. The leading approach has been that each of these forms emerges as a response to different types of uncertainty (Ghozzi et al., 2018; Krzeminska et al., 2013; Menard, 2013; Parmigiani, 2007). At least three of these types have been analyzed (Menard et al., 2014; Schnaider et al., 2018): (1) market uncertainty, capturing situations in which agents are uncertain about the fluctuations of supply and demand and market price volatility (Robertson and Gatignon, 1998); (2) technological uncertainty, in which agents are uncertain about the consequences of alternative technological solutions (Sorenson and Sørenson, 2001) and/or are confronted with rapid technological

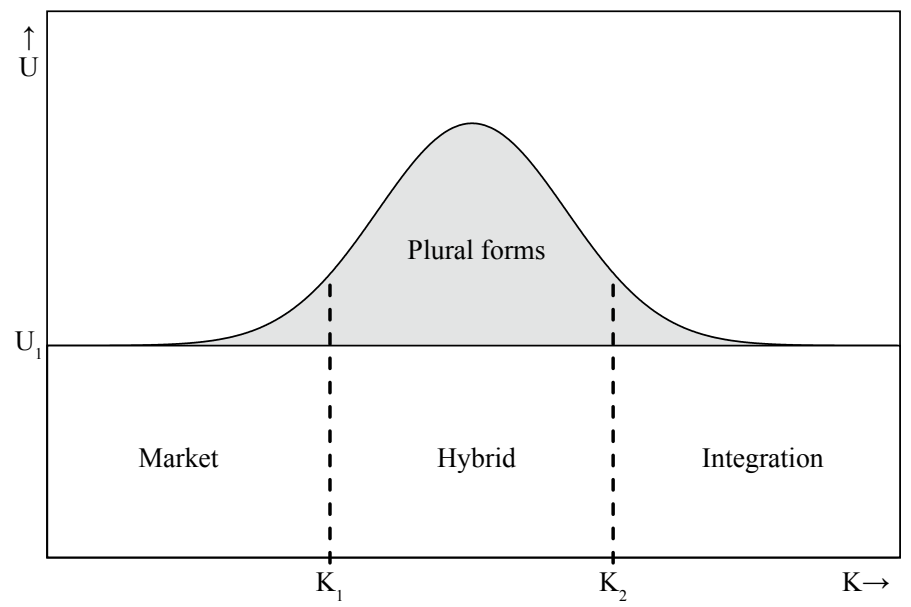

Figure 1. Transaction cost economics determinants for plural forms (Schnaider et al., 2018). 
changes $;{ }^{5}$ and (3) performance assessment uncertainty, whereby observing and measuring the adherence of transacting parties to the contractual arrangements is hard and/or it is not easy to measure the performance of these parties (Alchian and Demsetz, 1972; Barzel, 1982; Dutta et al., 1995; Krzeminska et al., 2013). The determinants for the choice of different types of plural forms can be summarized as follows:

Proposition 2: The type of uncertainty will play a major role in the types of organizational arrangements selected to compose the plural form.

Transactions subject to each of the types of uncertainty specified above (and intermediate levels of asset specificity) will face distinct challenges to be overcome. As the nature of these problems varies, so will the organizational arrangements to help deal with them. As a result, transactions subject to several types of uncertainty will combine alternative organizational arrangements, each of which suitable to deal with each of these types of uncertainty. This could be summarized as follows:

Proposition 3: The more types of uncertainty affecting a transaction, the more likely is the combo type of plural form (given intermediate levels of asset specificity).

\section{Empirical illustrations}

We make use of embedded clinical case studies (Baker and Gil, 2013; Eisenhardt, 1989; Yin, 2011). This is a single case study that is composed of a number of subunits that are individually analyzed and compared. For example, decisions within different business units composing a single large firm can be analyzed in isolation and also compared. However, because they are not independent, but part of a broader unit several characteristics are held constant. They are subject to the same organizational culture and the same set of internal rules. This allows us to place a larger emphasis on our variables of interest, namely transactional attributes, which vary among the different units, while keeping constant other factors that might otherwise interfere with our results (for example, different firm strategies, managerial perceptions, location, firm orientation, etc). We have selected a leading multiproduct company in the Organic market in Brazil: the Korin company. As we shall explain in more detail in the coming subsections, it offers a wide variety of agricultural goods, each of which with different specificities, purchasing conditions and characteristics while under the same overall market strategic positioning (high quality organic productions). Also, Korin relies on a large variety of organizational arrangements to procure and produce its products, making it fertile ground to confront our propositions.

\subsection{Data}

\section{- About Korin}

Korin is the largest and leading firm operating in the organic market in Brazil. This market generated BRL\$ 4.6 billion $^{6}$ in revenues in 2019 , representing a growth rate of $15 \%$ relative to the previous year. Korin alone generated BRL\$ 166 million $^{7}$ in 2019 (Korin, 2019), representing about 5\% of the entire organic market. This is a considerable market share, given that this market integrates over 65,000 producers, mostly small farmers (IPEA, 2020).

Korin was founded in 1994, occupying an area of 172 hectares in Ipeuna (in the countryside of Sao Paulo, Brazil), based on the principles of Nature Farming laid out by Mokiti Okada, a Japanese philosopher and spiritualist. This is a philosophical model that among other things, endorses the consumption of natural foods,

\footnotetext{
${ }_{5}^{5}$ Blockchain technology is a leading example of such rapid innovation and related uncertainty.

${ }^{6}$ About US\$ 1.15 billion considering the exchange rate at the time.

${ }^{7}$ About US\$ 41.2 million, considering the exchange rate at the time.
} 
free of the toxins coming from fertilizers and agrochemicals. ${ }^{8}$ Korin is a multiproduct company, offering a portfolio of 80 organic products. ${ }^{9}$ The firm regularly manages over 300 suppliers and sells its products in 1,400 stores throughout 23 states in Brazil out of 26 (ABRAS, 2015).

\section{- The subcases}

Out of this extensive portfolio, we have selected five subcases: two final products (organic and antibiotic-free poultry and organic eggs) and three critical inputs to them (regular and organic corn and regular soybeans). This selection of products captures the most important ones, in terms of revenue. In 2014, poultry represented about $75 \%$ of the firm's revenue, while the eggs accounted for about $9 \%$. In terms of volume, in 2014, Korin processed 210,000 tons of chicken and nearly 12 million eggs (Korin, 2015). The firm is also a pioneer in the production of organic and antibiotic-free poultry in Brazil.

Crucial to provide these two final products are regular soybeans, regular corn and organic corn, which serve as inputs to feed the birds. Out of these, organic corn is the main component used to feed Korin's chickens. Korin consumes over 1000 tons of the product each month, considering both the organic and regular varieties, which compose $65 \%$ of all the chickens feeding. It is also worth mentioning that regular soybeans and corn are allowed to compose the birds feeding up to a limit of $15 \%$ in volume in order to meet the legal requirements for the products to be sold as organic. This fact is important because of cost concerns: regular commodities tend to cost less than their organic varieties. Together, these three inputs represent $75 \%$ of the cost of producing both poultry and eggs. Figure 2 illustrates our selection.

To summarize, we took care to select inputs or products that would be meaningful to the firm. After all, it is in these transactions that organizational efficiency is critical to remain competitive in the market.

\subsection{Data collection}

We constructed a semi-structured questionnaire that guided our in-depth interviews. ${ }^{10}$ Two face-to-face interviews were made in 2014 together with the general manager, for about two hours each. We also visited the firm headquarters to verify the differentiated production process mentioned during said interviews. We triangulated that data with information collected with firm technicians working with each of the products at its headquarters. Finally, to double-check some general information provided by the firm and to fill out some gaps in our data, we relied on triangulation with secondary sources, such as documents, sector specific reports and other literature. Our objective in doing so is twofold. First, we intend to assess the

\footnotetext{
${ }^{8}$ Korin's natural production meets the requirements of the act 10.831, as of December $23^{\text {rd }} 2003$, which regulates the production of organic food in Brazil.

9 This includes poultry, eggs, fruit, vegetables, mineral water, microbiological fertilizers, coffee, and honey and derivatives (Korin, 2015).

${ }^{10}$ The interview guide is enclosed in the Supplementary Material. It was based on Menard et al. (2014), but adapted in order to capture the objectives and framework in this study. To this end, we have included questions on the different types of uncertainty and excluded other aspects that did not matter for our own objectives.
}

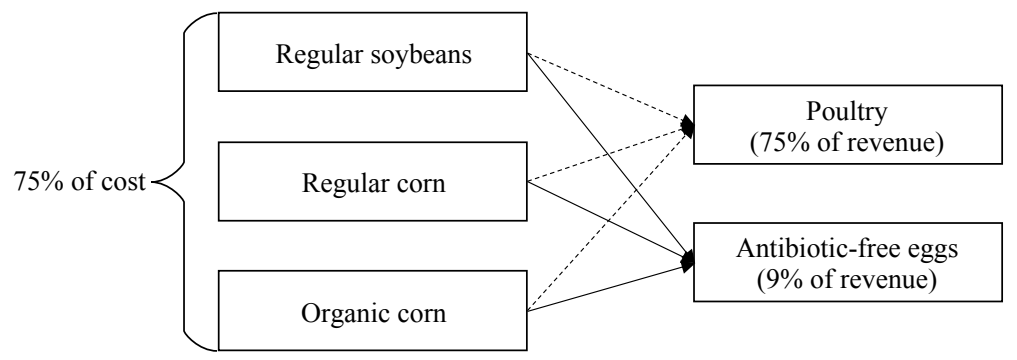

Figure 2. Case selection. 
plural form phenomenon through different perspectives, not only the interviewees' but also that expressed in the alternative secondary sources of data. Most importantly, we also seek to provide more reliability to our findings (Johnson et al., 2007).

Essentially, what we intend to capture with our data collection were both general characteristics of the company and specific characteristics of the transactions of interest (such as the historical path, the ways by which they are procured, the motivations for this choice, etc.). In that respect, we are first concerned with the ways by which each of the critical inputs are procured. We classify the alternative organizational arrangements in the following way: first, we divide the total quantity into what is obtained in-house versus what is outsourced. Next, we classify the percentage that is outsourced (when relevant) in three ways: spot market, relational contracts and formal contracts. Spot market denotes all purchases made without any form of implicit or explicit contract and whereby the identities of the suppliers are irrelevant as each of them can be easily replaced. In contrast, when relational contracts are used, parties are well-known, repeatedly transact with each other, and their identities matter in the procurement transaction, despite the lack of formal/explicit contracts. Reputational concerns are keys to enforce this kind of agreements. Finally, formal contracting refers to explicit procurement contracts between transacting parties where contractual commitment are enforced through reliance on the court system.

We capture the manager's qualitative perception about why the firm procures each input as such, as well as his qualitative perceptions on both asset specificity and uncertainty for each transaction of interest. Our questions captured the three types of uncertainty identified before: market, technological and performance assessment.

\section{Results and discussion}

Two out of the five subcases are procured with non-plural forms and three, by means of plural forms. For each of the products described below, we begin by explaining the means of procurement and follow with the discussion of the main drivers of this choice, as well as the main problems to be overcome (Table 1), according to Korin. Our intention in doing so is to capture the drivers for both the use of plural forms and for their variety.

\subsection{Non-plural forms}

\section{- Organic and antibiotic-free poultry}

Governance: Korin produces in-house $100 \%$ of its main product.

Asset specificity: Producing organic and antibiotic-free poultry involves very specific technology and very special care is needed to meet the legal requirements for the product to be certified. First, poultry is raised outdoor within a delineated area in the farm, where the birds can circulate in a low density of animals per square meter. Second, these animals are not pecked, and therefore, they become less likely to develop diseases typically associated with such practice. Finally, when they do become sick, they are treated solely with natural products. All this care requires specialized knowledge, which is hard to find on the market. To illustrate how specific an endeavor this is, developing said technology resulted from 10 years of intensive $\mathrm{R} \& \mathrm{D}$. The greatest challenge in this process was the development of the organic and antibiotic-free feeding for the chickens. Besides all the specificities that are necessary to produce these special varieties of poultry, the production process of poultry in general requires large dedicated investments in order to meet the scale requirements to be competitive in this industry.

Uncertainty: Market uncertainty, in the poultry supply chain in general, is quite significant. First, as already mentioned, because the market is dominated by large players selling both in domestic and in international 
markets, demand shocks, mainly overseas, cause great price volatility (either up or down). ${ }^{11}$ Second, because organic birds are fed solely with corn and soybeans (and their derivatives), their market price volatility introduces some significant uncertainty in the cost of the product (see the next subsections for more information on the price volatilities of these commodities). Therefore, because the poultry supply-chain bears significant uncertainties on both the supply and demand sides, we can consider it a highly uncertain market.

\section{- Regular soybeans}

Governance: Korin outsources $100 \%$ to suppliers with formal contracts.

Asset specificity: Regular soybeans are commodities and therefore, their level of asset specificity is low. Also, it is worth mentioning that, Brazil is the largest producer and exporter of soybeans in the world (USDA, 2020). Hence, this commodity is easy to obtain in the country and suppliers can be fairly easily substituted whenever needed.

Uncertainty: Korin's major concern relative to soybeans is its price volatility (market uncertainty): in general, it tends to vary on average between 10 to $40 \%$ per year; considering both the Brazilian and the international market. Given that the company acquires a relatively large quantity of this input, and considering the impact of the price volatility of said commodity on the costs of producing both eggs and poultry; it is imperative that it devises mechanisms to deal with the uncertain market conditions leading to this highly volatile scenario. One of these consists of procuring regular soybeans by means of formal contracts. In doing so, price is determined upfront and hence, the firm is able to smooth the price paid for soybeans in an average range that is neither too high not too low; but more predictable.

\subsection{Plural forms}

\section{- Antibiotic-free eggs}

Governance: Korin obtains antibiotic-free eggs by combining some in-house production with different types of formal contracts, as shown in Table 1. There are three types of formal contracts, differing mainly in the degree of autonomy granted to producers. And this depends on the extent to which said producers control their assets and different steps in the supply chain (Figure 3). For instance, 29\% of Korin's outsourced antibioticfree eggs come from one producer of type A in Figure 3, owning and controlling the entire production process and delivering the eggs clean, classified, sanitarily inspected and packaged with Korin's brand. 14\% of Korin's antibiotic-free eggs come from one producer, which delivers the eggs to be cleaned, classified, sanitarily inspected and packaged by Korin, who then sells them (type B in Figure 3). Finally, the reminding part of Korin's outsourced antibiotic-free eggs come from three producers who are almost integrated to the company. They do not control the production process at all, but merely provide the workers and their physical structure required to produce these eggs. Korin, in turn, provides its own hens and technical assistance to these farmers. This is an interesting arrangement because in practice, these suppliers own the assets, but Korin is the one controlling them through contractual provisions (type $\mathrm{C}$ in Figure 3 ). ${ }^{12}$

Asset specificity: The production of organic and antibiotic-free eggs requires differentiated techniques. These are very similar to the special care taken with poultry. For instance, hens are raised free, fed mostly with organic corn and soybeans. Also, it is mandatory that investments be made in order to obtain the organic and antibiotic-free certification that is valued by consumers. Finally, a critical step in the production and sale of these eggs is an inspection process that is required by the Ministry of Agriculture in order for the product to

\footnotetext{
11 On average, there was $15 \%$ per year volatility over the last 11 years, with a variation from $8 \%$ per year to $22 \%$ per year. Organic products are at least as volatile as their regular counterparts.

12 This is very similar to the contracts found in the US broiling industry where integrators heavily control their suppliers through contractual specifications (see for instance Knoeber, 1989). See also Hueth et al. (1999) for analysis of the fruit and vegetable contracts and Baker et al. (2011) for a more formal analysis.
} 
Table 1. Forms of procurement.

\begin{tabular}{|c|c|c|c|c|c|}
\hline \multirow[t]{2}{*}{ Governance/product } & \multicolumn{3}{|c|}{ Plural forms } & \multicolumn{2}{|c|}{ Non-plural forms } \\
\hline & $\begin{array}{l}\text { Antibiotic- } \\
\text { free eggs }\end{array}$ & $\begin{array}{l}\text { Regular } \\
\text { corn }\end{array}$ & $\begin{array}{l}\text { Organic } \\
\text { corn }\end{array}$ & $\begin{array}{l}\text { Organic } \\
\text { poultry }\end{array}$ & $\begin{array}{l}\text { Regular } \\
\text { soybeans }\end{array}$ \\
\hline In-house production & $23 \%$ & - & $15 \%$ & $100 \%$ & - \\
\hline Outsourced production & $77 \%$ & $100 \%$ & $85 \%$ & - & $100 \%$ \\
\hline Spot market & - & - & - & - & - \\
\hline Relational suppliers (no contract) & - & $99.8 \%$ & $30 \%$ & - & - \\
\hline Local producers - type 1 & - & $4 \%$ & - & - & - \\
\hline Local producers - type 2 & - & $5 \%$ & - & - & - \\
\hline Local producers - type 3 & - & $40 \%$ & - & - & - \\
\hline Cereal companies & - & $50 \%$ & - & - & - \\
\hline Suppliers with formal contract & $100 \%$ & $<0.1 \%$ & $70 \%$ & - & $100 \%$ \\
\hline Type 1 & $29 \%$ & - & - & - & - \\
\hline Type 2 & $14 \%$ & - & - & - & - \\
\hline Type 3 & $57 \%$ & - & - & - & - \\
\hline Cereal companies & - & - & $100 \%$ & - & - \\
\hline Futures market & - & $<0.1 \%$ & - & - & - \\
\hline
\end{tabular}
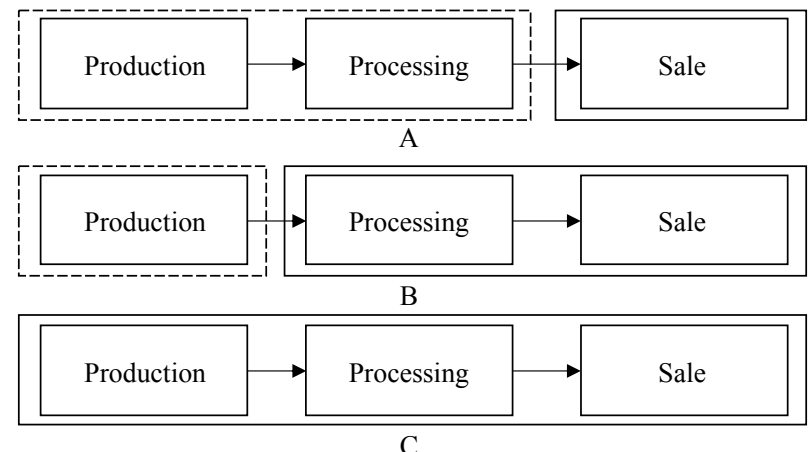

Figure 3. Producers of antibiotic-free eggs. The solid line represents the steps controlled by Korin.

be sold in Brazil. This requires special knowledge about all the legal requirements. However, differently than poultry, there is neither such a strict scale constraint nor is there the need for high dedicated infrastructure investments and this is why the level of asset specificity is intermediate.

Uncertainty: Uncertainty is very high in the production of antibiotic-free eggs. First, there is technological uncertainty related to the differentiated production process. As mentioned before, developing such technology was by no means an easy task, and neither was it convincing suppliers to adopt it. Furthermore, maximizing productivity according to the parameters that determine it is also not as trivial as it may seem. There can be variations according to the breed or to the way birds are fed, that are still unknown and need to be experimented for.

Second, there is high performance assessment uncertainty because it is very hard (if not impossible) to measure the suppliers' marginal productivity and thus determine their cost. To begin with, it is impossible to determine at the outset the lifecycle stage on which each of the suppliers' hens are. And therefore, it is hard to determine whether or not the supplier is lying about its productivity (and therefore, cost). This is why monitoring and control mechanisms are so important: they signal to the supplier that Korin has information 
to estimate (benchmark) their lifecycle and productivity, even approximately. This prevents suppliers from declaring to be in an early stage as to sell a smaller quantity for a higher price, when they are actually producing more and delivering the remaining quantity elsewhere (because they can't always be in the early stage and because Korin can mimic their production).

Main problem to be overcome with plural forms: Korin uses plural forms to deal with both performance assessment and technological uncertainties. First, when no information is available, suppliers can opportunistically conceal their real productivity in order to maximize their individual gains. By producing some eggs in-house, Korin is able to benchmark its suppliers' productivity. Also, as mentioned earlier, the production of this special type of eggs requires differentiated techniques and finding suppliers willing to adopt them is not a trivial endeavor. In fact, it has been extremely hard to find these suppliers and teach them the special care required. By producing some eggs in-house, Korin can signal the profitability of this technological choice to potential suppliers. In addition, it has developed some valuable expertise that can be shared.

\section{- Regular corn}

Governance: Korin obtains its regular corn according to Table 1. Regular corn is outsourced mostly by means of different relational contracts, although a very small quantity comes from occasional formal contracts with large suppliers or from the futures market. The main differences in terms of relational contracts are associated with the type of suppliers (local producers vs large cereal companies) the company is dealing with and with the way by which the sale occurs (local producers types A, B and C, Figure 4).

First, the relationship with large firms and with small local producers is naturally different (they are organized differently, for instance, small producers relate to Korin themselves, while large firms have multiple managers performing this task) and therefore, the natures of these relational contracts differ accordingly. What is most interesting within these differences is that local producers can sell their corn in three different ways.

In the first one (type A), Korin pays for the corn before delivery, according to price and quantities that are agreed upon beforehand. In the second case (type B), the payment does occur when the corn is actually received. However, both price and quantity are fixed ex-ante. Finally, Korin obtains most of its corn from type C suppliers. Korin stores its type C suppliers' corn in its own storage facilities, without buying it. It only buys this corn whenever each supplier decides to sell it at the market price relative to when the sale occurs. This way of buying corn is more costly because storing it requires space (out of scarce land) and special facilities, but it helps guarantee the supply of the product. After all, storing the product is an informal mechanism of enforcement such that the stored corn will be sold exclusively to Korin.

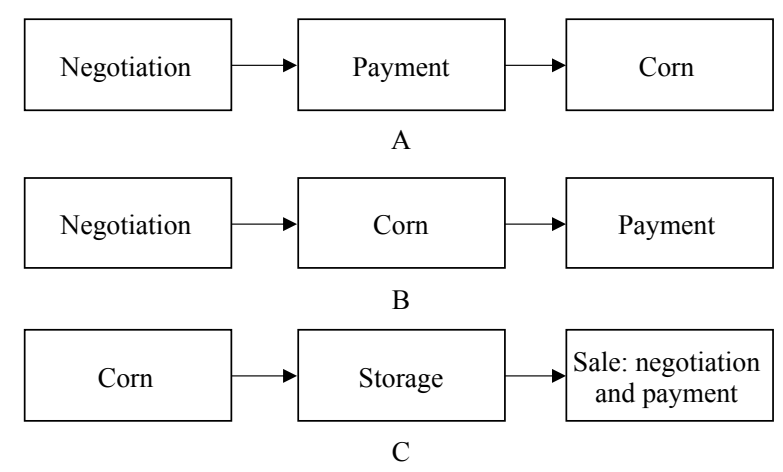

Figure 4. Different contracting practices with regular corn suppliers. 
Asset specificity: Regular corn is a commodity, but not all corn is suitable to feed Korin's chicken. They can be fed solely with high quality variety of the product, i.e. whole grains. Low quality corn, in general, includes crashed grains, which are harmful for the birds. Hence, high quality corn requires some special care to guarantee that there will only be whole grains.

Uncertainty: There is a lot of volatility in corn price index (volatility varied, on average, between 15 and $25 \%$ per year in Brazil, according to data retrieved from Cepea - Center for Advanced Studies in Applied Economics, 2015). Although this index does not reflect differences in quality, it still serves as an illustration of how prices varied over time. This market volatility proves to be a threat to Korin because corn and soybeans prices correspond to $75 \%$ of the company's cost of feeding the animals. Variations in the market price of this input lead to important cost variation. This is why it is imperative that Korin devises mechanisms to neutralize the high market volatility. Add to this the fact that high quality corn is not as available on the market as the mainstream variety, so Korin must absolutely guarantee the supply of the product.

Main problem to be overcome with plural forms: high quality corn is crucial to Korin because it feeds its most important products (poultry and eggs) at a lower cost than the organic variety, despite being used in smaller proportions. Therefore, it must not only secure its procurement, but also its price. The main problem with regular corn is that there is significant market volatility (market uncertainty), which implies variations in both quantity and price. To help overcome this problem, Korin turns to different types of hybrid arrangements, each of which helping to secure prices and quantities in face of different market conditions.

\section{- Organic corn}

Governance: Korin obtains organic corn by combining some in-house production with formal contracts, as shown in Table 1. Organic corn is mainly bought through formal contracts together with cereal companies in Brazil. These are signed for each harvest, having the price being established ex-ante as roughly $30 \%$ more than that of regular corn. Korin negotiates with its suppliers together with other firms, who collectively bargain with suppliers (purchase group). They have more bargaining power than each firm in isolation would have and are able to get better prices.

Asset specificity: Producing organic corn is not as trivial as it may seem at the outset. It requires specific knowledge to enable a good productivity (while the yield of conventional corn is on average that of 10 to $12 \mathrm{~kg}$ per hectare that of the organic variety, on average, is roughly half). This is due to two factors. First, organic corn grows together with other useless bushes and therefore, this not only reduces the average yield per hectare but also requires that special care be taken to ensure that those bushes will be properly identified and removed. Second and relatedly, the organic production of corn requires more labor force than the conventional variety, mostly because of the bushes and the special care that is needed to separate it. As a result, organic corn cannot be as easily found on the market because producers tend to perceive it as a product with high cost and low productivity.

Uncertainty: Determining the average productivity at the outset is not that easy. This is a major concern to the company because it should compensate its suppliers according to their productivity. And in the absence of control mechanisms, these can easily and opportunistically declare a lower productivity (performance assessment uncertainty) to deliver a smaller quantity at a higher price, while selling the remaining production elsewhere. This is why, according to Korin, its own production is so strategic: it allows to better estimate its suppliers' productivities because it can get more information.

Besides the performance issue, there is significant market uncertainty in the production of organic corn. As most agricultural goods, corn is very sensitive to unforeseen climatic variations or diseases. Because organic corn is such a critical input for the firm, it must absolutely secure its supply. Hence, if it relied on a single supplier or solely in in-house production, these hazards could cause it to lose the entire production. So diversifying suppliers is key to dealing with uncertain market conditions. Moreover, organic corn does 
not grow uniformly all year around, but at certain times. And these periods vary according to the region of Brazil where it is being produced. This requires that the company buy the product from other locations in order to meet its demand all year-round. And this becomes even more relevant because organic corn cannot be stored like the regular variety. It can only be kept for about two months because no chemicals can be used in the storage facility to guarantee the integrity of the product.

Main problems to be overcome with plural forms: plural forms help Korin overcome both performance assessment and market uncertainties. By producing some corn in-house, Korin can benchmark its suppliers' productivities, and hence, deal with the performance issue. But most importantly, plural forms help the firm deal with market uncertainty. Although organic corn is not its main product or core business, it feeds its main products, so Korin must guarantee its supply. Given the specificities of organic corn, it is imperative that it is obtained from different locations in Brazil. One way of doing this would be to acquire land in these different locations to rely solely on vertical integration. But this would require a lot of capital investments which are not feasible. Besides, even if it were feasible, because there is market uncertainty, it would be extremely hard to guarantee the production of enough corn to appropriately meet its demand, without excess supply or demand. Hence, the best way of overcoming these problems is to rely on plural forms.

\subsection{A comparative perspective}

We can see that the procurement of each of the products described above is subject to different types and levels of uncertainty and mostly to intermediate levels of asset specificity.

Asset specificity: As shown in previous subsections, the procurement of most products (regular corn and organic corn and soybeans) involves intermediate levels of asset specificity, although these levels vary considerably within the intermediate range. For instance, regular products present a much lower level of asset specificity than their organic varieties. Two exceptions to this intermediate range were found. First, the procurement of regular soybeans involves very low levels of asset specificity, while that of organic and antibiotic free poultry involves higher levels. Low asset specificity refers to a level of specificity that is lower than $\mathrm{K} 1$ in Figure 1; intermediate asset specificity denotes levels between $\mathrm{K} 1$ and $\mathrm{K} 2$ in Figure 1 and high asset specificity regards levels that are higher than $\mathrm{K} 2$. This implies variability in the intermediate range, since some will be closer to K1 and others to K2.

Uncertainty: Considerable uncertainty surrounds the procurement of all the products discussed, albeit of varying type (market, technological, performance assessment) and of variable intensities. In that respect, we must stress that we did not attempt to quantify the level of uncertainty, but rather to qualify the dominant type, for the different sub-cases so as to get a better understanding of the circumstances under which each transaction takes place. We showed that market uncertainty surrounds almost all the analyzed transactions, except for the eggs. Table 2 summarizes this argumentation.

Table 2. A comparative perspective.

\begin{tabular}{|c|c|c|c|c|c|}
\hline Product & $\begin{array}{l}\text { Asset } \\
\text { specificity }\end{array}$ & Uncertainty & $\begin{array}{l}\text { Type of } \\
\text { uncertainty }\end{array}$ & $\begin{array}{l}\text { Plural } \\
\text { forms }\end{array}$ & Governance \\
\hline Regular soybeans & Low & Intermediate & Market & No & Hybrids \\
\hline Regular corn & Intermediate & Intermediate & Market & Yes & Within (relational hybrids) \\
\hline Organic corn & Intermediate & High & $\begin{array}{l}\text { Market and } \\
\text { performance }\end{array}$ & Yes & $\begin{array}{l}\text { Combo (hierarchies }+ \\
\text { different relational hybrids) }\end{array}$ \\
\hline $\begin{array}{l}\text { Antibiotic-free } \\
\text { eggs }\end{array}$ & Intermediate & High & $\begin{array}{l}\text { Technological and } \\
\text { performance }\end{array}$ & Yes & $\begin{array}{l}\text { Combo (hierarchies }+ \\
\text { different formal hybrids) }\end{array}$ \\
\hline Poultry & High & High & Market & No & Hierarchies \\
\hline
\end{tabular}




\section{Analyses: what explains the diversity of plural forms?}

\subsection{Prevalence of plural forms}

Considering the comparison of the five subcases, we have represented these products in the framework shown in Figure 1. The result is represented in Figure 5. While the slope of the curve can vary, what matters most are the reasons underlying the placement of each product as such and the motivations for its procurement.

Regular soybeans and poultry are the only products outside the 'plural zone', i.e. obtained by means of nonplural forms. Regular soybeans are obtained exclusively by means of formal contracts because the level of specific investments involved is relatively low and therefore, a very high level of uncertainty would be required in order to outperform this organizational solution. Nonetheless hybrid arrangements have been used instead of the spot market to help the firm deal with a higher level of uncertainty. Conversely, the production of poultry involves almost dedicated assets, such that no other arrangement can outperform hierarchy. These findings are consistent with TCE and its asset specificity story. There are three cases in the plural zone: regular corn, organic corn, and antibiotic-free eggs. They present intermediate degrees of asset specificity and significant levels of uncertainty. Thus, their procurement is made by means of plural forms. This is consistent with P1.

\subsection{Diversity of plural forms}

Table 1 describes the various combinations of alternative organizational arrangements used to produce the final products. For instance, organic corn is obtained both internally and by means of formal contracts; whereas regular corn is solely outsourced with a mixture of different types of relational contracts. Finally, antibiotic-free eggs are obtained in a way that is similar to organic corn: part is produced in-house and part is outsourced by means of different types of formal contracts (rather than relational like in the case of the regular corn).

In Table 2 we classify this diversity of plural forms using the classification by Schnaider et al. (2018): between, within and combo types of plural forms. Although we cannot establish causal relationships with the case study method, there is exploratory evidence in favor of a correlation between these typologies and the main problems to be overcome with the use of plural forms. Namely, these are different types of uncertainties. For instance, while regular corn is subject to high market uncertainty, organic corn is subject to both high market and high performance assessment uncertainties. Finally, antibiotic-free eggs are subject to both high

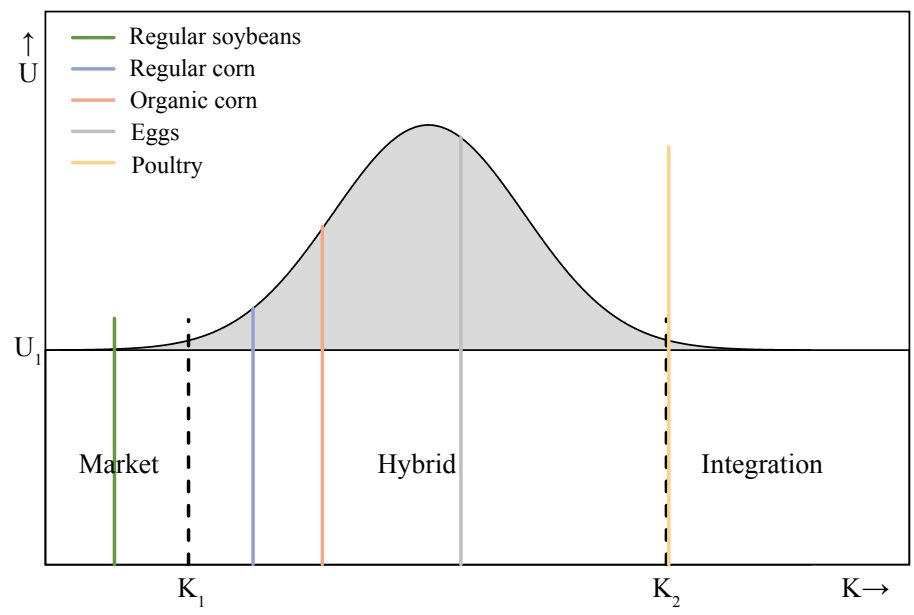

Figure 5. Empirical findings (adapted from Schnaider et al. (2018)). 
technological and performance assessment uncertainties. This finding suggests that the type of plural form will help firms deal with different typologies of uncertainties, providing evidence in favor of P2.

Also, we can see both in the case of organic corn and of organic and antibiotic-free eggs that there is more than one type of uncertainty is affecting the procurement transactions: market and performance assessment in the case of organic corn and technological and performance assessment uncertainties in the case of the eggs. These are also the only cases where the combo type of plural forms are present. This suggests that firms concomitantly rely on different types of plural forms to simultaneously deal with different types of uncertainty. Hence, there is evidence in favor of P3.

Another aspect that stood out in all the three cases involving plural forms is that plural from diversity of goes beyond the distinction between the categories of 'between, within and combo' plural forms. Even within these categories, plural forms differ in the specific weights (\%) of each organizational arrangement composing them. For example, while both the procurement of antibiotic-free eggs and organic corn are made by means of the combo-type of plural form, the former involves $23 \%$ of in-house production and the latter $15 \%$. By comparing the percentages that are made in-house in the three transactions relying on the use of plural forms (shown in Table 1) and their representation in Figure 3, we can see that those involving more specific assets to be secured presented a higher percentage made in-house. We can see that as the level of asset specificity decreases, so does the percentage made in-house. Despite exploratory, this evidence is both consistent with traditional TCE and suggests that the role of asset specificity, within the plural form, is more important than previously believed. Hence, we derive the following proposition:

Proposition 4: Within the plural form, the level of asset specificity will play a major role in determining the degree of coordination, such that the higher the level of asset specificity, the higher the percentage produced in-house (or quasi-integrated).

\section{Final remarks}

In this paper, we sought to empirically analyze the extent to which asset specificity and uncertainty can be used to describe and explain the variety of plural forms. We also intended to explore their respective roles in the specific composition of the plural form. Indeed, our empirical case illustrated first that the variety and diversity of plural forms go way beyond the reliance on both market and vertical integration, as previously admitted. Firms can combine hybrids with vertical integration, markets and hybrids and so on. Firms can even use more than two different governance structures to manage a transaction. These alternative types of plural forms carry different governance properties, which not only differ within these typologies, but also, between other governance solutions. The Korin case provides an empirical illustration of such diversity and allows us to observe an extension of the traditional TCE framework to account for plural forms and their diverse compositions. While we found that both asset specificity and uncertainty are important determinants for the plural form decision, each of these variables will play a different role when it comes to describing and explaining its composition.

Our empirical cases indicate that for intermediate levels of asset specificity, the type of uncertainty affecting a particular transaction will play a dominant role when determining the type of plural form. This is because each type of uncertainty will require different governance properties to be dealt with. The cases of regular and organic corn and eggs provide indications in that respect.

They also indicate that the higher the level of uncertainty, i.e. the more different types of uncertainty are combined, the more types of arrangements will be used to compose the plural form, i.e. the more diverse will the plural form be. Despite exploratory, our findings also shed light on the role played by asset specificity in the composition of the plural form, indicating that its role might be greater than previously admitted. As shown in proposition $\mathrm{P}_{4}$, we find that within the plural form (and given intermediate levels of asset specificity and high levels of uncertainty), the higher the level of asset specificity, the larger the percentage produced 
in house (or quasi-integrated). We are aware of the limitations of our method, but our findings shed light on a potential path to be confirmed in future studies.

Also, many unanswered questions remain in this respect. For example, what else explains the percentages of each type of arrangement composing the plural form? Are these percentages stable over time, or do they adjust to help dealing with emerging issues? What are the effects of regulatory constraints (like safety and liability regulation) on the composition of plural forms? These questions demonstrate the extensive and challenging research agenda yet to be explored when it comes to the heterogeneity of plural forms in supply chain management.

\section{Supplementary material}

Supplementary material can be found online at https://doi.org/10.22434/IFAMR2021.0056

\section{Interview guide.}

\section{Acknowledgements}

The authors would like to thank the Sao Paulo State Research Foundation for the financial support (grants no. 2011/23495-0 and 2013/00296-7).

\section{References}

Alchian, A.A. and H. Demsetz. 1972. Production, information costs, and economic organization. The American Economic Review 62(5): 777-795.

Associação Brasileira de Supermercados (ABRAS). 2015. Korin Agropecuária cresce acima do mercado brasileiro de alimentos e lança produtos orgânicos e sustentáveis na APAS 2015. Available at: https:// www.abras.com.br/clipping/geral/50543/korin-agropecuaria-cresce-acima-do-mercado-brasileirode-alimentos-e-lanca-produtos-organicos-e-sustentaveis-na-apas-2015

Baker, G., R. Gibbons and K.J. Murphy. 2008. Strategic alliances: bridges between 'islands of conscious power'. Journal of the Japanese and International Economies 22(2): 146-163.

Baker, G., R. Gibbons and K.J. Murphy. 2011. Relational adaptations. Working paper, MIT, Cambridge, MA, USA.

Baker, G.P. and R. Gil. 2013. Clinical papers in organizational economics. In: R. Gibbons and J. Roberts (eds.) The handbook of organizational economics. Princeton University Press, Princeton, NJ, USA, pp. 193-212.

Barzel, Y. 1982. Measurement cost and the organization of markets. Journal of Law \& Economics 25(1): 27-48.

Bradach, J.L. 1998. Franchise organizations. Harvard Business Press, Boston, MA, USA.

Bradach, J.L. and R.G. Eccles. 1989. Price, authority, and trust: from ideal types to plural forms. Annual Review of Sociology 15(1): 97-118.

Carrer, M.J., H.M. De Souza Filho and M.D.M.B. Vinholis. 2014. Plural forms of governance in the beef industry: a case study in Brazil. British Food Journal 116(4): 643-661.

David, R.J. and S.K. Han. 2004. A systematic assessment of the empirical support for transaction cost economics. Strategic Management Journal 25(1): 39-58.

Dutta, S., M. Bergen, J.B. Heide and G. John. 1995. Understanding dual distribution: the case of reps and house accounts. Journal of Law, Economics, \& Organization 11(1): 189-204.

Dyer, J.H. 1996. Does governance matter? Keiretsu alliances and asset specificity as sources of Japanese competitive advantage. Organization Science 7(6): 649-666.

Eisenhardt, K.M. 1989. Building theories from case study research. Academy of Management Review 14(4): 532-550.

Feltre, C. and L.F.D. Paulillo. 2015. Plurality in different groupings: sugarcane supply in Brazil. British Food Journal 117(9): 2265-2281. 
Fernández-Barcala, M., M. González-Díaz and E. Raynaud. 2017. Contrasting the governance of supply chains with and without geographical indications: complementarity between levels. Supply Chain Management: an International Journal 22(4): 305-320. https://doi.org/10.1108/SCM-05-2016-0161

Fernández-Olmos, M., J. Rosell-Martínez and M.A. Espitia-Escuer. 2009. Vertical integration in the wine industry: a transaction costs analysis on the Rioja DOCa. Agribusiness: an International Journal 25(2): 231-250.

Ghozzi, H., C. Soregaroli, S. Boccaletti and L. Sauvée. 2016. Impacts of non-GMO standards on poultry supply chain governance: transaction cost approach vs resource-based view. Supply Chain Management: an International Journal 21(6): 743-758.

Ghozzi, H., S. Platoni, P. Tillie and C. Soregaroli. 2018. TCE determinants and governance forms in the EU 'non-GMO' soybean supply chain. Food Policy 78: 68-80.

Glaser, B. and A. Strauss. 1967. The discovery of grounded theory. Weidenfield \& Nicolson, London, UK, pp. 1-19.

Grandori, A. 2015. Improving organization forms in the agri-food industry. British Food Journal 117(10): 2418-2434.

Hueth, B., E. Ligon, S.A. Wolf and S. Wu. 1999. Incentive instruments in fruit and vegetable contracts: input control, monitoring, measuring, and price risk. Review of Agricultural Economics 21: 374-389.

Instituto de Pesquisa Econômica Aplicada (IPEA). 2020. Produção e consumo de alimentos orgânicos no Brasil e no mundo. IPEA, Brasília, Brazil. Available at: http://repositorio.ipea.gov.br/bitstream/11058/9678/1/ TD_2538.pdf

Johnson, R.B., A.J. Onwuegbuzie and L.A. Turner. 2007. Toward a definition of mixed methods research. Journal of Mixed Methods Research 1(2): 112-133.

Knoeber, C. 1989. A real game of chicken: contracts, tournaments, and the production of broilers. Journal of Law, Economics \& Organization 5(2): 271-292.

Korin, 2015. Relatório 2015 de ações Socioambientais - Korin Agropecuária. Available at: http://www. korin.com.br/wp-content/uploads/2017/05/relatorio-2015.pdf

Korin. 2019. Korin fecha 2019 com 12\% de crescimento. Available at: https://www.korin.com.br/imprensa/ korin-fecha-2019-com-12-de-crescimento/

Krzeminska, A. 2009. Determinants and management of make-and-buy: and extension to TCE. Gabler, Wiesbaden, Germany.

Krzeminska, A., G. Hoetker and T. Mellewigt. 2013. Reconceptualizing plural sourcing. Strategic Management Journal 34(13): 1614-1627.

Lafontaine, F. 1992. Agency theory and franchising: some empirical results. RAND Journal of Economics 23(2): 263-283.

Lafontaine, F. and K. Shaw. 2005. Targeting managerial control: evidence from franchising. RAND Journal of Economics 36(1): 131-150.

Macher, J.T. and B.D. Richman. 2008. Transaction cost economics: an assessment of empirical research in the social sciences. Business and Politics 10(1): 1-63.

Masten, S.E. 2000. Transaction-cost economics and the organization of agricultural transactions. In: M.R. Baye (ed.) Industrial organization. Emerald Group Publishing Limited, Bingley, UK, pp. 173-195.

Ménard, C. 2013. Plural forms of organization: where do we stand? Managerial and Decision Economics 34(3-5): 124-139.

Ménard, C. 2018. Organization and governance in the agrifood sector: how can we capture their variety? Agribusiness 34(1): 142-160.

Ménard, C., M.S.M. Saes, V.L.S. Silva and E. Raynaud. 2014. Challenges to economic organization: plural forms. Atlas, São Paulo, Brazil.

Parmigiani, A. 2007. Why do firms both make and buy? An investigation of concurrent sourcing. Strategic Management Journal 28(3): 285-311.

Raynaud, E., P.S.B. Schnaider and M.S.M. Saes. 2019. Surveying the economics of plural modes of organization. Journal of Economic Surveys 33(4): 1151-1172.

Robertson, T.S. and H. Gatignon. 1998. Technology development mode: a transaction cost conceptualization. Strategic Management Journal 19(6): 515-531. 
Ruben, R., D. Boselie and H. Lu. 2007. Vegetables procurement by Asian supermarkets: a transaction cost approach. Supply Chain Management: an International Journal 12(1): 60-68. https://doi. org/10.1108/13598540710724365

Schnaider, P.S.B., C. Ménard and M.S.M. Saes. 2018. Heterogeneity of plural forms: a revised transaction cost approach. Managerial and Decision Economics 39(6): 652-663.

Siggelkow, N. 2007. Persuasion with case studies. Academy of Management Review 50(1): 20-24.

Sorenson, O. and Sørensen, J.B. 2001. Finding the right mix: franchising, organizational learning, and chain performance. Strategic Management Journal 22(6-7): 713-724.

Strauss, A.L. 1987. Qualitative analysis for social scientists. Cambridge University Press, Cambridge, UK.

United States Department of Agriculture (USDA). 2020. Market and trade data. Foreign Agricultural Service, USDA, Washington, DC, USA. Available at: https://apps.fas.usda.gov/psdonline/app/index.html\#/ app/downloads

Vinholis, M.D., H.M. De Souza Filho, M.J. Carrer and F.R. Chaddad. 2014. Transaction attributes and adoption of hybrid governance in the Brazilian cattle market. Journal on Chain and Network Science 14(3): 189-199.

Williamson, O.E. 1985. The economic institutions of capitalism: firms, markets and relational contracting. Free Press, New York, NY, USA.

Williamson, O.E. 1991. Comparative economic organization: the analysis of discrete structural alternatives, Administrative Science Quarterly 36(2): 269-296.

Williamson, O.E. 2008. Outsourcing: transaction cost economics and supply chain management. Journal of Supply Chain Management 44(2): 5-16.

Woldie, G.A. and E.A. Nuppenau. 2011. A contribution to transaction costs: evidence from banana markets in Ethiopia. Agribusiness 27(4): 493-508.

Yin, R.K. 2011. Applications of case study research. SAGE Publishing, Thousand Oaks, CA, USA.

Zylbersztajn, D. 1996. Governance structures and agribusiness coordination: a transaction cost economics approach. In: R. Goldberg (ed.) Research in domestic and international agribusiness management. Vol. 12. Harvard University, Cambridge, MA, USA, pp. 245-310. 
